\title{
Ideological purity not required
}

Published online: 13 July 2011

(C) Psychonomic Society, Inc. 2011

I have just put the final editorial touches on an interesting new article describing a series of experiments dealing with a topic that is very close to my own area of research. As it happens, I really disagree with the authors' conclusions. That said, I am not going to tell you about the disagreement nor am I going to take advantage of my position as editor by using this platform to argue my corner. In fact, I am not even going to tell you who wrote the piece. My purpose in writing this brief editorial is to make it clear that agreement with the dearly held theoretical positions of the editors or reviewers is not a prerequisite for publication in Attention, Perception, \& Psychophysics. The article that I am thinking about is a particularly nice example because the reviewers also disagreed with the article's theoretical stance. We all know cases in which a manuscript does not get accepted and in which, at the very least, the author believes that the cause was the ideological opposition of a reviewer or editor. Many authors have requested that Drs. X \& Y not be asked to review their manuscript because of such conflicts. I wouldn't want to argue that this never happens - even at $A P \& P$ - but here is what we hope will happen when your controversial and/or combative paper gets submitted.

1. If you are attacking the position of Drs. $\mathrm{X} \& \mathrm{Y}$, odds are that we will send it to one of them to review. After all, they are probably the most interested readers on the planet. It is true that they are likely to have more critical comments than average. People do like to defend their positions. (Note: We would hope that when you are in the position of Dr. X or Dr. Y, your review will be rigorous but not obstructionist.)
2. We will also send the manuscript to two or three experts who are not part of the argument. If the other reviewers see merit in the manuscript, it would not be rejected simply on the basis of a harshly negative review from Drs. X \& Y.

3. You would need to respond to the reviews. If $X \& Y$ say that you are misrepresenting their position, you might have to change what you say about them. If X\&Y (or any other reviewers) can argue that your data do not support your conclusions, you are going to need to fix that. However, there comes a point where solid data are solid data and we are just arguing about different perspectives about the meaning of those data. At that point, we do not want to hold up publication over disagreements about an explanation grounded in the data and the literature.

Of course, in the real world, what a reviewer thinks is a fundamental question about the data, an author might see as a petty effort to delay publication. Nevertheless, we will continue to strive to publish excellent science accompanied by coherent and scholarly Discussion sections but we will not insist that authors, reviewers, and editors agree about ideology prior to publication. Let us know how we are doing. Feel free to send an email to me or to any associate editor (wolfe@search.bwh.harvard.edu).

\section{Jeremy M Wolfe}

Editor

Attention, Perception, and Psychophysics

wolfe@search.bwh.harvard.edu 